\title{
ANALISIS MARKOV CHAIN TERHADAP PERSEDIAAN: STUDI KASUS PADA CV SINAR BAHAGIA GROUP
}

\author{
Haryadi Sarjono; Edwin; Himawan Sentosa; Frendy Bong \\ Jurusan Manajemen, Fakultas Ekonomi dan Komunikasi, BINUS University \\ Jln. K.H. Syahdan No. 9, Palmerah, Jakarta Barat 11480
}

\begin{abstract}
Supply is one of the most important factors for the company, but there are still so many companies who don't understand about how to monitoring their supplies so there will be not too much or too little supplies for them to manage. Some of the important things are to know how many supplies that a company should prepare to fulfill the needs of supply for the next period. This essay is aimed to investigate whether there was a shift/moving towards the supplies and the factor, which trigger the moving, how many supplies that the company should have and the cost that they have to pay to fulfill the supplies. The result shows that there was a moving of supplies, which has been cause by some factors. The kind of research that being used is a descriptive research, with a quantitative data. And the methods that being used is the case study, The point of this research is because of the moving of supplies that has been caused by the age of the supplies, the company have to calculate how many supplies that they should have to fulfill the needs of the next period.
\end{abstract}

Keywords: supplies, Markov Chain, forecasting

\begin{abstract}
ABSTRAK
Persediaan merupakan salah satu faktor yang penting bagi suatu perusahaan tetapi masih banyak perusahaan yang tidak mengetahui bagaimana memonitoring persediaannya sehingga tidak terlalu banyak atau tidak terlalu sedikit. Beberapa hal yang penting adalah mengetahui berapa banyak permintaan yang harus dipersiapkan oleh perusahaan untuk memenuhi persediaan untuk periode mendatang. Penulisan ini bertujuan untuk meneliti apakah terjadi pergeseran terhadap persediaan dan faktor apakah yang memicu pergeseran tersebut, berapakah persediaan yang harus dimiliki oleh perusahaan dan berapakah biaya yang harus dikeluarkan persediaan untuk memenuhi persediaan tersebut. Hasil penilitian menyatakan bahwa terjadi pergeseran terhadap persediaan oleh karena beberapa faktor. Jenis Penelitian yang digunakan adalah penelitian deskriptif, dengan jenis data kuantitatif. Metode penelitian yang digunakan adalah metode Markov Chain. Kesimpulan dari penelitian ini adalah karena terjadi pergeseran dalam persediaan yang disebabkan oleh umur persediaan tersebut maka perusahaan harus memperhitungkan berapakah persediaan yang harus kita punya untuk memenuhi permintaan untuk periode mendatang.
\end{abstract}

Kata kunci: persediaan, Rantai Markov, forecasting 


\section{PENDAHULUAN}

Persediaan bahan baku di dalam perusahaan adalah merupakan hal yang sangat wajar untuk dikendalikan dengan baik. Setiap perusahaan yang menghasilkan produk pasti memerlukan persediaan bahan baku ini. Baik disengaja ataupun tidak perusahaan yang bersangkutan ini akan menyelenggarakan persediaan bahan baku yang menunjang jalannya proses produksi. Dalam penyelenggaraan persediaan bahan baku ini akan diusahakan agar bahan baku yang ada di dalam perusahaan akan dapat mempunyai biaya persediaan yang serendah mungkin. CV Sinar Bahagia adalah perusahaan yang bergerak dibidang produksi batako (bahan baku untuk membangun perumahan). Bahan baku untuk memproduksi batako ini adalah semen dan pasir dengan perbandingan 1 sak semen dan $1 \mathrm{~m}^{3}$ pasir dapat memproduksi batako sebanyak 100 buah.

Pada kenyataannya pesanan yang datang pada perusahaan lebih banyak semen dibandingkan dengan pasir, sehingga sering terjadi terhentinya pelaksanaan proses produksi. Dilain pihak persediaan bahan baku yang cukup besar dalam perusahaan ini juga akan membawa berbagai macam akibat yang akan merugikan perusahaan pula. Persediaan yang diselenggarakan dalam jumlah besar mengakibatkan terjadinya biaya-biaya persediaan bahan baku menjadi besar pula. Besarnya biayabiaya persediaan dapat mengurangi keuntungan yang seharusnya bisa dicapai oleh perusahaan ini. Disamping itu resiko kerusakan bahan baku juga semakin tinggi, sehingga mutu semen akan menurun jika tidak disimpan dengan baik. Keadaan tersebut tentunya mengakibatkan berkurangnya keuntungan yang diperoleh perusahaan. Selain itu juga menyebabkan kehilangan pelanggan karena ketidakmampuan perusahaan menyediakan kebutuhan pelanggan tepat pada waktunya.

Adapun tujuan untuk momecahkan permasalahan ini adalah menentukan biaya perencanaan persediaan bahan baku yang optimal serta menentukan biaya perencanaan persediaan bahan baku yang optimal.

\section{Kajian Pustaka}

Persediaan adalah suatu aktiva yang meliputi barang milik perusahaan dengan maksud dijual dalam suatu periode usaha yang normal, atau persediaan barang-barang yang masih dalam pengerjaan/proses produksi; persediaan barang baku yang menunggu penggunaannya dalam suatu proses produksi (Assauri, 2008).

Jadi, pengertian dari pengendalian persediaan dapat dikatakan suatu kegiatan untuk menentukan tingkat dan komposisi pengaturan dan pengawasan atas pelaksanaan pengadaan bahan yang diperlukan sehingga sesuai dengan yang dibutuhkan dan biaya yang serendah-rendahnya agar perusahaan dapat melindungi kelancaran produksi dan penjualan serta kebutuhan-kebutuhan pembelanjaan perusahaan. Biaya-biaya yang digunakan dalam analisis persediaan (Amelia, et al., 2009), meliputi biaya pesan (ordering cost), biaya simpan (carrying cost), biaya kehabisan persediaan (stockout cost) dan biaya pembelian (purchase cost).

\section{METODE}

Untuk menyelesaikan permasalahan tersebut diperlukan data yang berhubungan dengan permasalahan yang ada. Adapun langkah-langkah untuk mendapatkan data tersebut antara lain tahap pertama yaitu survey perusahaan dengan tujuan untuk mendapatkan gambaran awal mengenai permasalahan apa yang dapat diangkat untuk mengadakan penelitian. Tahap kedua yaitu study literature yang dilakukan untuk mendukung dalam menyelesaikan permasalahan. Tahap ketiga yaitu identifikasi masalah dan pengumpulan data-data yang diperlukan seperti data permintaan bahan baku, 
harga bahan baku, biaya pemesanan dan penyimpanan. Tahap keempat yaitu melakukan pengolahan data, dan melakukan analisa data dengan menggunakan perencanaan pengendalian persediaan dengan metode Markov Chain. Dan tahap kelima yaitu menarik kesimpulan dari hasil pengolahan serta analisis data yaitu persediaan bahan baku yang optimal serta biaya persediaan yang optimal.

\section{HASIL DAN PEMBAHASAN}

\section{Data Pemakaian} pada Tabel 1.

Data pemakaian material selama 6 bulan dapat dilihat dari data permintaan produk seperti

Tabel 1 Tabel Pemakaian Semen selama 6 bulan

\begin{tabular}{|c|c|c|c|c|}
\hline & $\begin{array}{c}\text { Periode } \\
\text { (t) }\end{array}$ & $\begin{array}{c}\text { Penjualan } \\
\text { Batako (Kg) }\end{array}$ & $\begin{array}{c}\text { RM : Semen } \\
\text { (Kg) }\end{array}$ & $\begin{array}{l}\text { Harga Total } \\
\text { (IDR) }\end{array}$ \\
\hline 1 (Juli) & 1 & 8000 & 2000 & Rp2.200.000 \\
\hline 2 & 2 & 4000 & 1000 & Rp1.100.000 \\
\hline 3 & 3 & 15000 & 3750 & Rp4.125.000 \\
\hline 4 & 4 & 3000 & 750 & Rp825.000 \\
\hline 5 (Agustus) & 5 & 10000 & 2500 & $\mathrm{Rp} 2.750 .000$ \\
\hline 6 & 6 & 12000 & 3000 & Rp3.300.000 \\
\hline 7 & 7 & 3000 & 750 & Rp825.000 \\
\hline 8 & 8 & 5000 & 1250 & Rp1.375.000 \\
\hline 9 (September) & 9 & 7000 & 1750 & Rp1.925.000 \\
\hline 10 & 10 & 10000 & 2500 & $\mathrm{Rp} 2.750 .000$ \\
\hline 11 & 11 & 9000 & 2250 & $\mathrm{Rp} 2.475 .000$ \\
\hline 12 & 12 & 10000 & 2500 & $\mathrm{Rp} 2.750 .000$ \\
\hline 13 (Oktober) & 13 & 4000 & 1000 & Rp1.100.000 \\
\hline 14 & 14 & 6000 & 1500 & Rp1.650.000 \\
\hline 15 & 15 & 13000 & 3250 & Rp3.575.000 \\
\hline 16 & 16 & 7000 & 1750 & Rp1.925.000 \\
\hline 17 (November) & 17 & 5000 & 1250 & Rp1.375.000 \\
\hline 18 & 18 & 6000 & 1500 & Rp1.650.000 \\
\hline 19 & 19 & 11000 & 2750 & Rp3.025.000 \\
\hline 20 & 20 & 8000 & 2000 & $\mathrm{Rp} 2.200 .000$ \\
\hline 21 (Desember) & 21 & 13000 & 3250 & Rp3.575.000 \\
\hline 22 & 22 & 14000 & 3500 & Rp3.850.000 \\
\hline 23 & 23 & 2400 & 600 & Rp660.000 \\
\hline 24 & 24 & 600 & 150 & Rp165.000 \\
\hline \multicolumn{2}{|c|}{ Grand Total } & 186000 & 46500 & Rp 51.150.000 \\
\hline
\end{tabular}

Sumber: Perusahaan (2010)

\section{Perhitungan Penentuan Optimum Persediaan dan Total Cost}

Besarnya persediaan di Gudang adalah $1.200 \mathrm{Kg}$

Harga Semen per $\mathrm{Kg} \quad=\mathrm{Rp} 1.100,-$

Biaya Pesan $\quad=\operatorname{Rp} 430.000,-$

Biaya Penyimpanan $\quad=\operatorname{Rp~30,-}$ x $1200 \mathrm{Kg}$ x 30 hari $=\operatorname{Rp} 1.080 .000,-=0,33 \%$

$\begin{array}{ll}\text { Biaya Penyusutan } & =0,80 \%+ \\ \text { Total Biaya Penyimpanan } & =1,13 \%\end{array}$

Biaya Penyimpanan Semen per bulan $=1,13 \%$ x $1200 \mathrm{~kg}$ x Rp 1.100,- x state i

Biaya kekurangan Persediaan $\quad=R p 430.000+(R p 1.100 \times 1200 \mathrm{~kg})$ 
data, yaitu:

Berdasarkan Tabel 1, data-data itu akan dimuat secara statistik ke dalam pengelompokan kelas

Jangkauan $=$ Data Terbesar - Data Terkecil $=3750-150=3600$

Jumlah Kelas $=1+3,3 \log \mathrm{n}=1+3,3 \log 24=5,54=6$

Interval $=3600 / 6=600$

Diasumsikan bahwa Persediaan Awal =0, 600, 1200, 1800, 2400, 3000

Berdasarkan ketetapan Markov Chain, bahwa pemberian keputusan $\mathrm{x}$, suatu state dari system mengalami transisi dari state $\mathrm{i}$ ke state $\mathrm{j}=\mathrm{I}+\mathrm{x}$-d dengan probabilitas $\mathrm{Pij}(\mathrm{x})=\mathrm{P}(\mathrm{d})$

Biaya Pesan $=\operatorname{Rp} 430.000$

Biaya Simpan $=$ jumlah material $\mathrm{x}$ harga

$$
=2500 \times \mathrm{Rp} 1.100=\mathrm{Rp} 2.750 .000
$$
(modus).

Jumlah material yang diambil adalah jumlah kuantitas yang paling banyak muncul di tabel

Kemudian dimulai perhitungan Markov Chain untuk tiap baris state, yaitu:

$$
\begin{aligned}
& \text { Untuk } i=0 ; x=600 ; j i k a j=0 \\
& \begin{aligned}
\text { Maka } j=i+x-d \\
0=0+100-d \\
d=600
\end{aligned}
\end{aligned}
$$

Probabilitas $\mathrm{P}_{\mathrm{ij}}=\mathrm{P}_{0,0}(600)$

$$
=\mathrm{P}(\mathrm{d}>=100)=1
$$

Untuk probabilitas lainnya $=0$

Shortage Cost $=$ Biaya pesan + Biaya simpan $\left[\sum(\mathrm{d}-\mathrm{i}-\mathrm{x}) \mathrm{P}(\mathrm{d})\right]$

$=\operatorname{Rp} 430.000+\operatorname{Rp} 2.750 .000[(1200-600) 0.42+(1800-600) 0.17+(2400-600) 0.13+(3000-$ $600) 0.08+(3600-600) 0.04]$

$=\operatorname{Rp} 2.755 .930 .000,-$

Matriks Probabilitas Transisi:

$$
\begin{aligned}
& \sim \dot{\sim} \dot{\sim}^{1} \dot{\sim}^{1} \dot{\sim} \dot{\sim}^{1} . \\
& \dot{\sim} \dot{\sim} \dot{\sim}^{1} \dot{\sim}^{1} \dot{\sim} \quad \dot{\sim}^{1} \text {. } \\
& \dot{\sim} \dot{\sim} \dot{\sim}^{1} \dot{\sim}^{1} \dot{\sim} \dot{\sim}^{1} \text {. } \\
& \dot{\sim} \dot{\sim}^{1} \dot{\sim}^{1} \dot{\sim} \dot{\sim}^{1} \text {. } \\
& \dot{\sim} \dot{\sim}^{1} \dot{\sim}^{1} \dot{\sim} \dot{\sim}^{1} \text {. } \\
& \dot{\sim} \dot{\sim} \dot{\sim}^{1} \dot{\sim}^{1} \dot{\sim} \dot{\sim}^{1} \text {. } \\
& \dot{\sim} \dot{\sim} \dot{\sim}^{1} \dot{\sim}^{1} \dot{\sim} \dot{\sim}^{1} \\
& \text {..1.1. } 1
\end{aligned}
$$

Perhitungan biaya optimalisasi menggunakan formula:

$$
\begin{aligned}
& \mathrm{f}_{\mathrm{i}}^{(\mathrm{k})}=\mathrm{C}_{\mathrm{i}}\left(\mathrm{X}_{\mathrm{i}}^{(\mathrm{k})}\right)+\alpha \Sigma \mathrm{P}_{\mathrm{ij}}\left(\mathrm{X}_{\mathrm{i}}^{(\mathrm{k})}\right) \mathrm{f}_{\mathrm{J}}^{(\mathrm{k})} \\
& \mathrm{f}_{0}{ }^{(0)}=860.000+0,96\left(0,04 \mathrm{f}_{0}{ }^{(0)}+0,08 \mathrm{f}_{600}{ }^{(0)}+0,13 \mathrm{f}_{1200}{ }^{(0)}+\right. \\
& \left.0,17 \mathrm{f}_{1800}{ }^{(0)}+0,42 \mathrm{f}_{2400}{ }^{(0)}+0,17 \mathrm{f}_{3000}{ }^{(0)}\right) \\
& \mathrm{F}_{600}{ }^{(0)}=1.308 .666+0,96\left(0,04 \mathrm{f}_{0}^{\left({ }^{(0)}\right.}+0,08 \mathrm{f}_{600}{ }^{(0)}+0,13 \mathrm{f}_{1200}{ }^{(0)}+\right. \\
& \left.0,17 \mathrm{f}_{1800}{ }^{(0)}+0,42 \mathrm{f}_{2400}{ }^{(0)}+0,17 \mathrm{f}_{3000}{ }^{(0)}\right)
\end{aligned}
$$




$$
\begin{aligned}
& \mathrm{F}_{1200}{ }^{(0)}=1.757 .332+0,96\left(0,04 \mathrm{f}_{0}^{(0)}+0,08 \mathrm{f}_{600}{ }^{(0)}+0,13 \mathrm{f}_{1200}{ }^{(0)}+\right. \\
& \left.0,17 \mathrm{f}_{1800}{ }^{(0)}+0,42 \mathrm{f}_{2400}{ }^{(0)}+0,17 \mathrm{f}_{3000}{ }^{(0)}\right) \\
& \mathrm{F}_{1800}{ }^{(0)}=2.205 .998+0,96\left(0,04 \mathrm{f}_{0}^{(0)}+0,08 \mathrm{f}_{600}{ }^{(0)}+0,13 \mathrm{f}_{1200}{ }^{(0)}+\right. \\
& \left.0,17 \mathrm{f}_{1800}{ }^{(0)}+0,42 \mathrm{f}_{2400}{ }^{(0)}+0,17 \mathrm{f}_{3000}{ }^{(0)}\right) \\
& \mathrm{F}_{2400}{ }^{(0)}=2.654 .664+0,96\left(0,04 \mathrm{f}_{0}{ }^{(0)}+0,08 \mathrm{f}_{600}{ }^{(0)}+0,13 \mathrm{f}_{1200}{ }^{(0)}+\right. \\
& \left.0,17 \mathrm{f}_{1800}{ }^{(0)}+0,42 \mathrm{f}_{2400}{ }^{(0)}+0,17 \mathrm{f}_{3000}{ }^{(0)}\right) \\
& \mathrm{F}_{3000}{ }^{(0)}=3.103 .330+0,96\left(0,04 \mathrm{f}_{0}{ }^{(0)}+0,08 \mathrm{f}_{600}{ }^{(0)}+0,13 \mathrm{f}_{1200}{ }^{(0)}+\right. \\
& \left.0,17 \mathrm{f}_{1800}{ }^{(0)}+0,42 \mathrm{f}_{2400}{ }^{(0)}+0,17 \mathrm{f}_{3000}{ }^{(0)}\right)
\end{aligned}
$$

Linear programming diselesaikan dengan menggunakan software QM for Windows. Saat persediaan awalnya adalah 0 , maka penambahan optimalnya adalah 600 , bila persediaan awalnya adalah 100 , maka penambahan optimalnya adalah 500, dan bila persediaan awalnya adalah 200 , maka penambahan optimalnya adalah 400 , bila persediaan awalnya adalah 300 , maka penambahan optimalnya adalah 300 , dan bila persediaan awalnya adalah 400 , maka penambahan optimalnya adalah 200, bila persediaan awalnya adalah 500, maka penambahan optimalnya adalah 100 .

$$
\begin{aligned}
& \mathrm{f}_{100}{ }^{(0)}=31.660 .084 \\
& \mathrm{f}_{200}{ }^{(0)}=31.846 .554 \\
& \mathrm{f}_{300}{ }^{(0)}=32.033 .024 \\
& \mathrm{f}_{400}{ }^{(0)}=32.219 .494 \\
& \mathrm{f}_{500}{ }^{(0)}=32.405 .964 \\
& \mathrm{f}_{600}{ }^{(0)}=32.592 .434
\end{aligned}
$$

Hasil biaya tersebut kemudian disubsitusikan ke dalam persamaan linear dan didapatlah biaya persediaan minimumnya.

$$
\begin{aligned}
& \mathrm{f}_{600}{ }^{(1)}=31.660 .090 \\
& \mathrm{f}_{1200}{ }^{(1)}=31.846 .557 \\
& \mathrm{f}_{1800}{ }^{(1)}=32.033 .024 \\
& \mathrm{f}_{2400}{ }^{(1)}=32.219 .491 \\
& \mathrm{f}_{3000}{ }^{(1)}=32.405 .958 \\
& \mathrm{f}_{3600}{ }^{(1)}=32.592 .425
\end{aligned}
$$

Dilihat dari hasil penelitian diatas maka pergeseran tingkat persediaan awal atau perpindahan state dapat terjadi disebabkan beberapa hal, yaitu: (1) umur dari bahan baku yang relatif singkat dan rentan terhadap gangguan mengakibatkan tingkat rotasi yang tinggi; (2) tingkat permintaan produk yang sangat berfluktuasi sehingga sangat mempengaruhi persediaan bahan baku.

Dalam hal ini perusahaan bisa mengandalkan perhitungan persediaan ini menggunakan metode Markov Chain, mengingat hasil yang didapat bisa merefleksikan jumlah persediaan dengan menghubungkan biaya yang harus dikeluarkan oleh perusahaan, misalkan jumlah persediaan yang ada $2400 \mathrm{Kg}$, maka biaya persediaan minimumyang harus dikeluarkan sebanyak Rp.32.219.491,-,dengan hasil penelitian ini maka, perusahaan dapat menghemat demikian besar pengeluaran untuk pembelian bahan baku, karena dari awal sudah bisa diramalkan secara akurat dengan tingkat kesalahan hanya 4\%. 


\section{PENUTUP}

Keputusan dalam pemesanan bahan baku, pada mulanya hanya berdasarkan peramalan kebutuhan saja tanpa ada suatu metode khusus dalam membantu memecahkannya. Agar biaya persediaan bahan baku menjadi seoptimal mungkin, maka alangkah baiknya melakukan suatu analisa atau menggunakan suatu metode tertentu yang memang diciptakan untuk tujuan demikian, salah satunya adalah metode Markov Chain, mengingat perhitungan inventory menurut Markov Chain maka lebih akurat dibandingkan perhitungan persediaan lainnya, dimana hasil perhitungannya sudah mencerminkan jumlah unit persediaan dan biaya yang harus dikeluarkan.

\section{DAFTAR PUSTAKA}

Amelia,S., et al. (2009). Integrasi kebijakan persediaan-transportasi. Jurnal Teknik Industri, Vol 11 (1), 2009, pp.15-32.

Assauri, S. (2008). Manajemen produksi dan operasi. Fakultas Ekonomi Universitas Indonesia, Jakarta. 